\title{
Effects of thermal recycling temperatures on the
}

\section{reinforcement potential of glass fibers}

U. Nagel ${ }^{1}$, L. Yang ${ }^{1}$, C. C. Kao ${ }^{2}$, J. L. Thomason ${ }^{1}$

${ }^{1}$ University of Strathclyde, Department of Mechanical and Aerospace

Engineering

${ }^{2}$ University of Strathclyde, Design, Manufacture and Engineering Management 
U. Nagel, L. Yang, C. C. Kao, J. L. Thomason

75 Montrose Street, Glasgow G1 1XJ, United Kingdom.

ulf.nagel@strath.ac.uk; +44 (0) 1415745085

\section{Abstract}

In the present work the reinforcement potential of thermally recycled glass fibers in injection molded Polypropylene (PP) composites was investigated. Microbond tests showed that fiber sizing lost its compatibility to the PP matrix after exposure to temperatures of $250{ }^{\circ} \mathrm{C}$ in air. The drop of the adhesion between fibers and PP was mirrored by a large reduction of the tensile strength of the injection molded PP composites. In inert atmosphere the degradation of the fiber sizing and the reduction of the IFSS were less rapid than in air but no significant difference was observed above $400{ }^{\circ} \mathrm{C}$. It was concluded that thermally recycled glass fibers will require a post-treatment to act as an effective reinforcement in injection molded PP composites even if the thermal recycling was performed in an inert atmosphere. The post-treatment will need to improve the compatibility of the fibers to the polymer matrix and the fiber strength. 


\section{Introduction}

The development of a recycling process for end-of-life Glass Fiber Reinforced Plastics (GFRPs) has become important. GFRPs account for more than $90 \%$ of all produced composites. Landfilling of GFRP waste is rapidly becoming economically, environmentally and legislatively unacceptable [1-3].

Transportation and wind energy are major consumers of GFRPs [4]. The wind turbine industry is experiencing rapid growth and some countries like Germany have banned the disposal of GFRP in landfill. The European Union has released the 'End of Life Vehicles' directive which requires car manufacturers to increase the recyclability of cars to $85 \%$ by 2015 [1, 2]. In the light of these developments, the need for a cost-effective recycling process for GFRPs has become critical. Composites are generally difficult to recycle because they consist of at least two different phases. In addition, most glass fiber composites are based on thermoset matrices [3] which form chemical crosslinks and are generally not simple to reprocess.

Mechanical, chemical and thermal recycling processes to separate glass fibers from thermoset matrices have been investigated in several studies. The reinforcement efficiency of mechanically recycled fibers is low compared to new glass fibers because the fibers are short and the fiber surface is not clean.

Chemical recycling processes are still at an early stage of development and are often limited to specific polymer matrices or involve the use of hazardous chemicals $[1,3]$. Thermal recycling processes can provide relatively long and clean fibers without the use of chemicals. GFRPs were thermally recycled in a fluidized bed reactor [5] or via pyrolysis $[6,7]$. The recycled fibers were 
incorporated into dough molding compound (DMC) composites and bulk molding compound (BMC) composites. The mechanical properties of the composites decreased when new glass fibers were replaced by the thermally recycled glass fibers. The reduction of the composite properties can at least partially be attributed to a degradation of the glass fiber strength due to exposure to high temperatures. The strength reduction of glass fibers after exposure to high temperatures was found to be temperature and time dependent. Higher temperatures caused a larger drop of the tensile strength and the retained strength of the fibers decreased as a function of the time until it reached a very low asymptotic value [8]. According to Jenkins et al. [9] the strength reduction is caused by at least two different mechanisms. One mechanism is associated with the degradation of the glass fiber sizing. It was observed that glass fibers without protective sizing are more susceptible to the formation of surface flaws due to mechanical handling. The authors postulated that the second mechanism of strength loss can be attributed to a surface dehydroxilation or to structural changes of the glass itself [10].

Discontinuous glass fiber thermoplastic composites are an interesting potential application for fibers produced by GFRP thermal recycling processes such as the fluidized bed described by Kennerly et al [5]. Similar to other studies they investigated thermoset composites based on thermally recycled glass fibers [68]. Thermoplastic composites based on mechanically recycled glass fibers have also been studied $[11,12]$ but less work has been done on the performance of thermoplastic composites based on thermally recycled glass fibers. Roux et al. [13] thermally preconditioned glass fibers before composite processing and 
incorporated them into injection molded polypropylene (PP) composites. However, they performed the thermal preconditioning over a period of 12 hours which is significantly longer than a thermal recycling process would take and the aim of their study was to investigate the influence of coupling agents and glass fiber sizings on the performance of glass fiber PP composites. Their results demonstrated the importance of glass fiber sizing for glass fiber PP composites. Even after a prolonged thermal treatment the mechanical performance of the injection molded composites improved significantly when sizing was applied to the fibers. The authors explained the beneficial effect of the sizing with an improvement of the interfacial adhesion between fiber and matrix.

In the present study, the interfacial adhesion between fiber and matrix was studied in the light of the reinforcement potential of thermally recycled glass fibers. Sized glass fibers were thermally conditioned at different temperatures in air and inert atmosphere to imitate thermal recycling processes like the fluidized bed process [5] and pyrolysis [6]. Microbond tests were performed to study the effect of the thermal conditioning on the fiber sizing and the interfacial adhesion between glass fiber and PP. Glass fiber PP composites were injection molded and mechanically tested to assess the influence of the interfacial adhesion on the macromechanical composite performance.

\section{Experimental}

\subsection{Materials}

The present study is based on commercial Advantex glass fibers with a diameter of $12.7 \pm 0.1 \mu \mathrm{m}$. The fibers were received as chopped bundles with a 
polypropylene compatible sizing. The average length of the fibers was measured to be $3.33 \pm 0.04 \mathrm{~mm}$ which is significantly shorter than the nominal fiber length of $4 \mathrm{~mm}$ as stated by the manufacturer. SABIC $®$ PP $579 \mathrm{~S}$ Polypropylene (PP) was used as composite matrix. 1 wt\% Polybond 3200 maleic anhydride-grafted polypropylene (MAPP) by PP weight was used to improve the interaction between fiber and matrix.

The procedure of other studies was followed to perform the thermal preconditioning of the glass fibers $[9,14,15]$. A carbolite CWF 12/13 furnace was used to thermally precondition the glass fibers under air. The fibers were placed in a preheated furnace and treated at different temperatures. After 25 min the fibers were allowed to cool down at ambient temperature $\left(21 \pm 2{ }^{\circ} \mathrm{C}\right)$ outside of the furnace. A NETSZCH STA 449 F1 Jupiter® thermal analyzer was used to thermally precondition the glass fibers at different temperatures in a nitrogen atmosphere. The temperature profile consisted of dynamic section with a heating rate of $25^{\circ} \mathrm{C} / \mathrm{min}$ and an isothermal section of $25 \mathrm{~min}$. After the isothermal section the fibers were cooled down with a cooling rate of $25^{\circ} \mathrm{C} / \mathrm{min}$.

The temperature profile for the treatment in a nitrogen rich atmosphere was therefore similar but not identical to the temperature profile for the treatment in air. The temperature profile for the heat treatment in a nitrogen rich atmosphere resembled pyrolysis processes which are batch processes and involve heating up and cooling down of the pyrolysis reactor while the samples are inside the reactor $[6,7]$. The heating up and cooling down of the glass fibers in the thermal analyzer also ensured that the fibers were not exposed to air at any point of the 
thermal conditioning. The heat treatment under air simulates a fluidized bed process where the fibers are fed into the preheated fluidized bed [5].

A Betol BC25 single screw extruder was used to compound the PP and MAPP with the fibers that were thermally conditioned in air. The processing barrel zone temperatures were set to $170{ }^{\circ} \mathrm{C}-220^{\circ} \mathrm{C}$. The extruded material was drawn through a water bath and cut into pellets using a rotary cutter. The pelletized material was fed into an Arburg 170-90/200 injection molding machine to produce dog-bone shaped multipurpose test specimens (ISO 3167, Type B).

The barrel temperatures were set to $210^{\circ} \mathrm{C}-230^{\circ} \mathrm{C}$ and the mold temperature was set to $35^{\circ} \mathrm{C}$. The fiber weight fraction of the composites was measured to be $29.3 \pm 0.3$ wt $\%$ via ashing of the PP and weighting of the fibers. The void content of the composites was determined to $1.2 \pm 0.2 \%$ via density measurements according to ASTM 2734.

\subsection{Macromechanical testing}

The tensile tests of the injection molded composites were guided by the standard ISO 527. An Instron 5969 testing machine equipped with a $50 \mathrm{kN}$ load cell was used to perform the tensile test. The displacement rate was set to 1 $\mathrm{mm} / \mathrm{min}$ and the strain was recorded with a video extensometer. The unreinforced PP was tested in the same way like the composites but the displacement rate was increased to $5 \mathrm{~mm} / \mathrm{min}$ after reaching $5 \%$ strain to reduce the testing time.

\subsection{Microstructural characterization}

\section{Microbond tests}


The PP pellets were heated to $200{ }^{\circ} \mathrm{C}$ on a glass slide which was placed on a hot plate. After $45 \mathrm{~s}$ the PP pellets were molten and drawn to form fibers. The microbond tests were performed on the same glass fibers and PP that was used to prepare composite samples. Figure 1 illustrates the procedure of the microbond sample preparation. Tweezers were used to extract single fibers from fiber bundles. Great care was taken not to touch the center of the glass fibers. A single glass fiber was suspended on double sided sticky tape next to a bright desk light and a PP fiber was knotted around the suspended glass fiber. Then the free ends of the PP fiber were trimmed. It was necessary to trim the PP fiber close to the knot to reduce the droplet size of the microbond samples. Glass fibers that were exposed to high temperatures have a low tensile strength and might break during the microbond test. A small microbond droplet debonds at lower loads than a large droplet and reduces the probability of fiber breakage. To cut the PP fiber close to the knot the movement of the PP fiber was restrained by sticking the fiber ends to double sided sticky tape. Vanna's-Type microscissors (Straight $80 \mathrm{~mm}$ provided by Agar scientific) enabled high precision cutting of the PP fiber.

After cutting the PP fiber, the glass fiber with the PP knot was glued onto a washer. Two component Araldite epoxy adhesive was applied on top of the sticky tape and glass fibers. The PP droplets were formed at $220^{\circ} \mathrm{C}$ in an OV11 vacuum oven that was purged with nitrogen. A procedure as described by Yang and Thomason $[16,17]$ was used to test the microbond samples using washers instead of card frames as sample holders.

\section{Fiber length measurements}


A procedure similar to Hartwich et al [18] was used to determine the length of the glass fibers in the injection molded tensile bars. Glass fibers were extracted from injection molded tensile bars using an ashing process. The ashing process was performed in a programmable Carbolite CWF 12/13 furnace. Glass fibers from the center of the tensile bar were dispersed in water. The dispersion was diluted and poured into petri-dishes. The petri-dishes were placed into the dark field box of an IDM FASEP fiber length measurement system and scanned. The scanned images were analyzed using the macro of the IDM FASEP fiber length measurement system which is implemented into the Image Pro image analysis software. The same procedure including the ashing process was followed to determine the length of the as received fibers before composite processing.

\section{Thermal gravimetric analysis}

The weight loss of glass fibers due to exposure to high temperatures was measured using a TA Instruments Q50 thermogravimetric analyzer. The analysis was performed under air and nitrogen with a heating rate of $10^{\circ} \mathrm{C} / \mathrm{min}$.

\section{Results and Discussion}

\subsection{Thermal gravimetric analysis}

The data of the thermal gravimetric analysis (TGA) in Figure 2 indicates that the organic fraction of the glass fiber sizing degraded at elevated temperatures. Most of the mass loss was recorded below $300{ }^{\circ} \mathrm{C}$ when the TGA was performed in air. Similar to Feih et al. [8] the present study showed that the presence of oxygen promotes the degradation of the glass fiber sizing. No significant mass loss was observed below $300{ }^{\circ} \mathrm{C}$ under a nitrogen atmosphere. 
Above $450^{\circ} \mathrm{C}$ similar mass losses were observed under a nitrogen atmosphere and air. In contrast, Feih et al. [8] observed that the loss of ignition in the presence of air was higher than in a nitrogen atmosphere. They observed the formation of char on the fiber surface when the TGA was performed in a nitrogen atmosphere. In the present study the sizing was apparently completely decomposed. Both studies show that glass fibers will lose their sizing during a thermal recycling process even if they are processed under an inert atmosphere.

\subsection{Fiber-matrix adhesion determined from microbond tests}

Figure 3 shows the measured values for the apparent interfacial shear strength (IFSS) between PP and glass fibers that were preconditioned at different temperatures in air and nitrogen. Each data point represents at least 15 successfully debonded microbond samples. The IFSS decreased moderately due to the thermal preconditioning at $200{ }^{\circ} \mathrm{C}$ in air. A more pronounced drop was observed when the fibers were preconditioned at $250{ }^{\circ} \mathrm{C}$. This correlates well with the data of the thermal gravimetric analysis in Figure 2 which indicates that in air most of the PP optimized sizing degraded between $200{ }^{\circ} \mathrm{C}$ and 250 ${ }^{\circ} \mathrm{C}$. In contrast, when the fibers were treated in a nitrogen atmosphere the IFSS did not decrease below $300^{\circ} \mathrm{C}$ fiber preconditioning temperature. Similar to the weight loss in Figure 2 the drop of the IFSS was less steep when the fiber preconditioning was performed in nitrogen instead of air. However, little effect of the atmosphere was observed when the fibers were thermally conditioned at $400{ }^{\circ} \mathrm{C}$ or higher temperatures. Most thermal recycling processes in inert atmosphere require temperatures oft at least $400^{\circ} \mathrm{C}[6,7,19]$ and an additional 
incineration process might be used [6] to separate the fibers from residual char and contamination. Thus recycling of glass fiber composites in inert atmosphere does not help to preserve the surface functionality of the glass fibers.

SEM micrographs revealed that all microbond samples exhibited adhesive failure which indicates the absence of polymer matrix degradation [17]. Menisci similar to that observed in Figure 4 were found on the fiber surface of tested samples when the fibers were not preconditioned. These menisci indicate the presence of matrix cracking. However, the size of the menisci is relatively small which indicates that the influence of the matrix cracking on the debond force may be negligible [20]. Figure 5 illustrates the influence of fiber preconditioning on the load-extension curve after debond at the maximum load. Similar to Yang and Thomason [16] it was observed that the behavior of the load extension curves depended on the load when the fiber debonded. When the microbond droplets debonded at high loads the measured load dropped almost to zero and oscillated before reaching a slowly decreasing value. This slip-stick behavior was observed in other glass fiber PP systems with high adhesion. When the fibers were preconditioned at temperatures higher than $250^{\circ} \mathrm{C}$ the samples debonded at lower loads and no slip-stick effect was observed.

\subsection{Residual fiber length}

Each fiber length measurement as described above was repeated five times for each fiber preconditioning temperature. Thus the fiber length distributions in Figure 6 are based on the length of more than 5000 fibers. Table 1 shows the arithmetic mean value of the distribution and the standard deviation of the distribution itself. Similar to the study of Roux et al [13] the standard deviations 
of the fiber length distributions in the present study are relatively large. The large standard deviations are an effect of the wide range of the fiber length distributions. Table 1 also shows the standard deviations between five repeat measurements for each fiber preconditioning temperature. It can be seen that the standard deviations between the repeat measurements are small compared to the standard deviations of the fiber length distributions.

Figure 6 shows that the percentage in the range between $0 \mu \mathrm{m}$ and $299 \mu \mathrm{m}$ increased with the fiber preconditioning temperature. The percentage of longer fibers decreased with the fiber preconditioning temperature. These changes are also reflected by a decrease of the average fiber length in Table 1.

The length degradation of glass fibers in PP composites and other thermoplastic composites during liquid melt processing has been reported in numerous studies [21-28]. Fibers are broken during melt processing of thermoplastic composites due to fiber-polymer interactions, fiber-fiber interactions and fiber-processor surface interactions [21, 29]. The fiber-polymer interactions cause fiber buckling and breakage due to forces between the fibers and the polymer melt. The glass fibers in a polymer melt can be described as thin rods with a critical buckling radius inversely proportional to their tensile strength $[25,28]$. Thus the additional length degradation of thermally preconditioned glass fibers in the present study might partially be explained with a reduction of the fiber strength. The thermally preconditioned glass fibers might also have been more susceptible to fiber breakage due to fiber-fiber interactions and fiber processor surface interactions before the melting zone on the extruder. The fibers were received as chopped bundles with a protective sizing. 
The thermal gravimetric analysis data in Figure 2 indicates that the sizing of the glass fibers started to degrade between $200{ }^{\circ} \mathrm{C}$ and $250{ }^{\circ} \mathrm{C}$ under air. Thus the thermally preconditioned glass fibers may be less protected against wear between fibers and between the fibers and the processor surfaces.

\subsection{Tensile strength of the composites}

The tensile strength of the composites is plotted in Figure 7 as a function of the fiber preconditioning temperature in air. It is interesting to note that the tensile strength dropped sharply between $200{ }^{\circ} \mathrm{C}$ and $250{ }^{\circ} \mathrm{C}$ fiber preconditioning temperature. Higher fiber preconditioning temperatures caused a further reduction of the composite strength. After fiber preconditioning at $500{ }^{\circ} \mathrm{C}$ the composite strength dropped to $37.7 \pm 0.5 \mathrm{MPa}$ which is barely higher than the tensile strength of the unreinforced PP $(35.8 \pm 0.2 \mathrm{MPa})$. The strength of discontinuous glass fiber PP composites is influenced by the fiber content, fiber orientation, residual fiber length, fiber strength and the adhesion between fiber and matrix [13, 23, 24, 30-32]. All processing parameters were kept constant. Only the residual fiber length, fiber strength and the adhesion between fiber and matrix changed when the fibers were thermally conditioned. The residual fiber length dropped slightly between $200{ }^{\circ} \mathrm{C}$ and $250{ }^{\circ} \mathrm{C}$ fiber preconditioning temperature. However the drop of the residual fiber length is relatively small and Thomason et al. [23] showed that the tensile strength of glass fiber reinforced PP composites increases gradually with the residual fiber length. Thus the sharp drop of the composite tensile strength cannot be explained with the residual fiber length. The microbond test results in Figure 8 show the interfacial adhesion between fibers that were thermally conditioned in air and PP with $1 \%$ 
added MAPP. The values for the IFSS are higher than in Figure 3 because of the added MAPP. However, in both cases the IFSS dropped sharply between $200{ }^{\circ} \mathrm{C}$ and $250{ }^{\circ} \mathrm{C}$ preconditioning temperature. Higher fiber preconditioning temperatures caused only a minor further reduction of the IFSS. The fracture surface of the composites also indicated a reduction of the IFSS when the glass fibers were thermally preconditioned. Figure 9 shows the fracture surface of a composite reinforced with as received fibers and the fracture surface of a composite reinforced with fibers that were thermally conditioned at $200{ }^{\circ} \mathrm{C}$. Figure 10 shows the fracture surfaces of composites reinforced with fibers that were heat treated at $250{ }^{\circ} \mathrm{C}$ and $500{ }^{\circ} \mathrm{C}$. The fibers in Figure 10 are relatively clean while the fibers in Figure 9 are partially covered with PP. These types of SEM are often interpreted in terms of the apparent level of fiber-matrix adhesion in the composite although it has been shown that such conclusions can be misleading [33]. In any case the SEM evidence is not inconsistent with the suggestion that the composites based on "as received" glass fibers had a higher adhesion than the composites based on fibers that were preconditioned at 250 ${ }^{\circ} \mathrm{C}$ or higher temperatures. Figure 10 shows that SEM micrographs of composite fracture surfaces did not reveal any clear differences between 250 ${ }^{\circ} \mathrm{C}$ and $500{ }^{\circ} \mathrm{C}$ fiber preconditioning temperature. In both cases, the fibers are relatively clean.

The strength degradation of glass fibers due to exposure to elevated temperatures is well documented but only little strength loss was observed due to fiber treatment in the range of $200{ }^{\circ} \mathrm{C}$ to $300{ }^{\circ} \mathrm{C}$ for a period of time similar to that used in the present study $[8,9,15]$. Consequently, we conclude that the 
sharp drop of the composite strength between $200{ }^{\circ} \mathrm{C}$ and $250{ }^{\circ} \mathrm{C}$ fiber preconditioning temperature was caused by a degradation of the IFSS. Thus recycled glass fibers cannot act as an effective reinforcement in injection molded PP composites when the surface functionality has been degraded by the recycling process.

The authors believe that the glass fiber sizing degradation close to processing temperatures deserves further research. Most of the glass fibers will be embedded in the PP matrix during composite processing and the fiber preconditioning of this study does therefore not represent processing conditions. However, processing temperatures are often increased to up to 300 ${ }^{\circ} \mathrm{C}$ to increase the production throughput and even short exposure to these temperatures under air (e.g. when the polymer melt exits the extruder) might cause a severe degradation of the glass fiber sizing.

In addition to the reduction of the IFSS a different mechanism is involved with the reduction of the composite strength after fiber preconditioning at higher temperatures. It was demonstrated in several studies $[23,27,30,34]$ that the tensile strength of discontinuous glass fiber PP composites can be described with the Kelly-Tyson model. Thomason [24, 27, 34] used an iterative algorithm developed by Bowyer and Bader [35] and based on the Kelly-Tyson model to calculate the IFSS, fiber orientation and fiber stress at failure in discontinuous glass fiber PP composites. The same method was used to analyses the fiber stress at composite failure in the present study but IFSS values obtained from the microbond tests were used as input parameter. Figure 11 shows the calculated fiber stress at composite failure as a function of the fiber 
preconditioning temperature. Considering the experimental error, the fibers stress at composite failure did not change significantly due to the thermal preconditioning at $200^{\circ} \mathrm{C}$. Fiber preconditioning at $250^{\circ} \mathrm{C}$ caused a clear reduction of the fiber stress. The fiber preconditioning at $500{ }^{\circ} \mathrm{C}$ caused a further reduction of the fiber stress at composite failure. The fiber stress was reduced to $25 \%$ of the value of untreated fibers. Jenkins et al. [9] reported a strength loss of single fibers of the same relative magnitude when bundles of aminopropyltriethoxy silane sized fibers were thermally treated at similar conditions. However, care must be taken when comparing the fiber stress at composite failure with the single fiber strength since the thermal conditioning of the glass fibers also influenced other microstructural properties such as the IFSS and to a lesser extent the residual fiber length. In summary, the main drop of fiber stress in the composite was observed between $200{ }^{\circ} \mathrm{C}$ and $250{ }^{\circ} \mathrm{C}$ fiber preconditioning temperature. This drop can be attributed to a degradation of the IFSS. The drop of the fiber stress after preconditioning at higher temperatures may partially be explained by the related reduction of the fiber strength.

\subsection{Failure strain}

Similar to the tensile strength, the failure strain of the composites in Figure 12 decreased sharply between $200{ }^{\circ} \mathrm{C}$ and $250{ }^{\circ} \mathrm{C}$ fiber preconditioning temperature. This was followed by a drop to a minimum at $300{ }^{\circ} \mathrm{C}$ fiber preconditioning temperature and a partial recovery at $450{ }^{\circ} \mathrm{C}$ and $500{ }^{\circ} \mathrm{C}$. While the parameters that influence the strength and stiffness of glass fiber PP composites have been studied extensively, few parametric studies deal with the failure strain of discontinuous glass fiber PP composites. The consensus is that 
higher fiber contents cause a reduction of the failure strain because of fiber induced stress concentrations which cause matrix cracking [23, 26, 30, 36]. The influence of the residual fiber length is less clear. Spahr et al. [36] reported that long glass fiber PP composites had a lower failure strain than short fiber composites. In contrast, Thomason et al. [23, 30] did not observe a significant influence of the fiber length. In a different study [24] Thomason noticed that the addition of MAPP increased the failure strain of injection molded glass fiber PP composites. This might be attributed to an improved adhesion between fiber and matrix which prevents the formation of cracks between fiber and matrix. The adhesion between fiber and matrix might also explain the reduction of the composite failure strain in the present study. As shown in Figure 3 and Figure 8 the adhesion between fiber and matrix was poor after fiber preconditioning at $250^{\circ} \mathrm{C}$ in air which might have promoted the formation of cracks between fiber and matrix and subsequent failure of the composite. When the fibers were preconditioned at temperatures higher than $250^{\circ} \mathrm{C}$ the failure strain partially recovered. The stress-strain curves in Figure 13 show that the composites exhibited a ductile behavior and did not fail at the maximum load when the fibers were preconditioned at $500^{\circ} \mathrm{C}$. This indicates a matrix dominated composite behavior and explains the recovery of the failure strain.

\subsection{Modulus of the composites}

Figure 14 indicates that the Young's modulus of the composites decreased slightly when the glass fibers were thermally preconditioned before composite processing. Higher preconditioning temperature caused a larger reduction of the Young's modulus. The Young's modulus of discontinuous glass fiber PP 
composites is mainly influenced by the fiber content, fiber orientation and the residual fiber length $[23,24,31,36]$ Thus the reduction of the residual fiber length shown in Figure 6 might explain the behavior of the Young's modulus in the present study. It was reported that the modulus of glass fibers increased $[37,38]$ after exposure to elevated temperatures. However, other researchers did not observe an increase of the fiber modulus and no increase of the composite modulus was observed when the glass fibers were exposed to elevated temperatures before composite processing $[8,39]$. The data of the present study suggests either that the modulus of the glass fibers was not significantly changed due to the thermal preconditioning or that the effect was masked by the influence of the fiber length reduction.

\section{Conclusion}

The present study showed that glass fibers lost most of their reinforcement potential after exposure to temperatures of around $250{ }^{\circ} \mathrm{C}$ in air. The sharp drop of the tensile strength of the injection molded polypropylene (PP) composites between $200{ }^{\circ} \mathrm{C}$ and $250{ }^{\circ} \mathrm{C}$ fiber preconditioning temperature was attributed to a reduction of the adhesion between fiber and polypropylene rather than a reduction of the fiber strength. The surface functionality of recycled glass fibers is therefore critical for the reinforcement potential. Microbond tests and thermal gravimetric analysis showed that the degradation of the fiber sizing in a nitrogen atmosphere was less rapid than in air. However, when the fiber preconditioning was performed at $400{ }^{\circ} \mathrm{C}$ or above the atmosphere had only a minor effect on the interfacial adhesion between fibers and PP. Thus thermal recycling in nitrogen is not beneficial for the surface functionality of the fibers because they 
require temperatures of at least $400{ }^{\circ} \mathrm{C}$. Fibers that were thermally recycled in air and fibers that were thermally recycled in an inert atmosphere need further post treatment to improve the reinforcement effectivity. Such treatment will ideally need to regenerate both surface functionality of the glass fibers and the fiber strength.

\section{Acknowledgement}

The authors gratefully acknowledge the funding from Engineering and Physical Sciences Research Council through the project EP/I038616/1. The authors would also like to thank the Advanced Materials Research Laboratory (University of Strathclyde) for the use of the mechanical testing machines and the SEM. The help of Saudi Basic Industries Corporation for the supply of the polypropylene is also acknowledged. 


\section{References}

1. S. Job, ReinforcedPlastics., 57, 19 (2013).

2. Parliament of the European Union and European Council, "Directive 2000/53/EC of the European Parliament and of the Council of 18 September 2000 on end-of life vehicles" in Official Journal of European Communities (2000)

3. Y.Yang, R. Boom, B. Irion, D. van Heerden, P. Kuiper and H. de Wit., Chem. Eng. Process. Process Intensif., 51, 53 (2012).

4. T. Kraus, M. Kuehnel and E. Witten, Composites Market Report 2014 (2014), pp. 29-44.

5. J. R. Kennerley, R. M. Kelly, N. J. Fenwick, S. J. Pickering and C. D. Rudd, Compos. Part A Appl. Sci. Manuf., 29, 839 (1998).

6. A. M. Cunliffe and P. T. Williams, Fuel., 82, 2223 (2003).

7. A. Torres, I. De Marco, B. M. Caballero, M. F. Laresgoiti, M. J. Chomón and G. Kondra, Adv. Polym. Technol,. 32, 474 (2012).

8. S. Feih, E.Boiocchi, G. Mathys, Z. Mathys, A.G. Gibson and A.P. Mouritz, Compos. Part B Eng., 42, 350 (2011).

9. P. G. Jenkins, L. Yang, J. Liggat and J. L. Thomason, J. Mater. Sci., 50 1050 (2014).

10. M. D. Lund and Y. Yue, J. Am. Ceram. Soc., 93, 3236 (2010).

11. C. E. Kouparitsas, C. N. Kartalis, P. C. Varelidis, C. J. Tsenoglou and C.

D. Papaspyrides, Polym. Compos., 23, 682 (2002)

12. C. Bream and P. Hornsby, Polym. Compos., 21, 417 (2000).

13. C. Roux, J. Denault and M. F. Champagne, J. Appl. Polym. Sci., 78, 2047 (2000).

14. J. L. Thomason, C. C. Kao, J. Ure and L. Yang, J. Mater. Sci., 49, 153 (2013).

15. J. L. Thomason, L. Yang and R. Meier, Compos. Part A Appl. Sci. Manuf., 61, 201 (2014).

16. L. Yang and J. L. Thomason, Polym. Test., 31, 895 (2012). 
17. L. Yang and J. L. Thomason, Compos. Part A Appl. Sci. Manuf., 41, 1077 (2010).

18. M. R. Hartwich, N. Höhn, H. Mayr, K. Sandau and R. Stengler, "FASEP ultra-automated analysis of fibre length distribution in glass-fibrereinforced products" in Proceedings of SPIE Conference, 7389 (2009).

19. D. Akesson, Z. Foltynowicz, J. Christeen and M. Skrifvars, J. Reinf. Plast. Compos., 31, 1136 (2012).

20. M. Nishikawa, T. Okabe, K. Hemmi and N. Takeda, Int. J. Solids Struct., 45, 4098 (2008).

21. B. Fisa, Polym. Compos., 6. 232 (1985).

22. V. B. Gupta, R. K. Mittal, P. K. Sharma, G. Mennig, J. Wolters, Polym. Compos., 10, 8-15 (1989).

23. J. L. Thomason, Compos. Part A Appl. Sci. Manuf., 33, 1641 (2002).

24. J. L. Thomason, Compos. Sci. Technol., 62, 1455 (2002).

25. R. K. Mittal, V. B. Gupta, P. K. Sharma, Compos. Sci. Technol., 31, 295 (1988).

26. S.-Y. Fu, B. Lauke, E. Mäder, C.-Y. Yue and X. Hu, Compos. Part A Appl., Sci. Manuf. 31, 1117 (2000).

27. J. L. Thomason, Compos. Part A Appl. Sci. Manuf., 36, 995 (2005).

28. J. H. Phelps, A. I. Abd El-Rahman, V. Kunc and C. L. Tucker, Compos. Part A Appl. Sci. Manuf., 51, 11 (2013).

29. R. Turkovich and L. Erwin, Polym. Eng. Sci., 23, 743 (1983).

30. J. L. Thomason, M. A. Vlug, G. Schipper and H. G. L. T. Krikort, Compos. Part A Appl. Sci. Manuf., 27A, 1075 (1996).

31. S. F. Xavier and A. Misra, Polym. Compos., 6, 93 (1985).

32. V. B. Gupta, R. K. Mittal and P. K. Sharma, Polym. Compos. 10, 16 (1989).

33. S. Y. Fu, B. Lauke, Y. H. Zhang and Y.-W. Mai, Compos. Part A Appl. Sci. Manuf., 36, 987 (2005).

34. J. L. Thomason, Compos. Part A Appl. Sci. Manuf., 38, 210 (2007). 
35. W. H. Bowyer and M. G. Bader, J. Mater. Sci., 7, 1315 (1972).

36. D. E. Spahr, K. Friedrich, J. M. Schultz and R. S. Bailey, J. Mater., Sci. 25, 4427 (1990).

37. H. Otto, J. Am. Ceram. Soc., 44, 68 (1961).

38. L. Yang and J. L. Thomason, J. Mater. Sci., 48, 5768 (2013).

39. L. Yang, E. R. Sáez, U. Nagel and J. L. Thomason, Compos. Part A Appl. Sci. Manuf., 72, 167 (2015). 


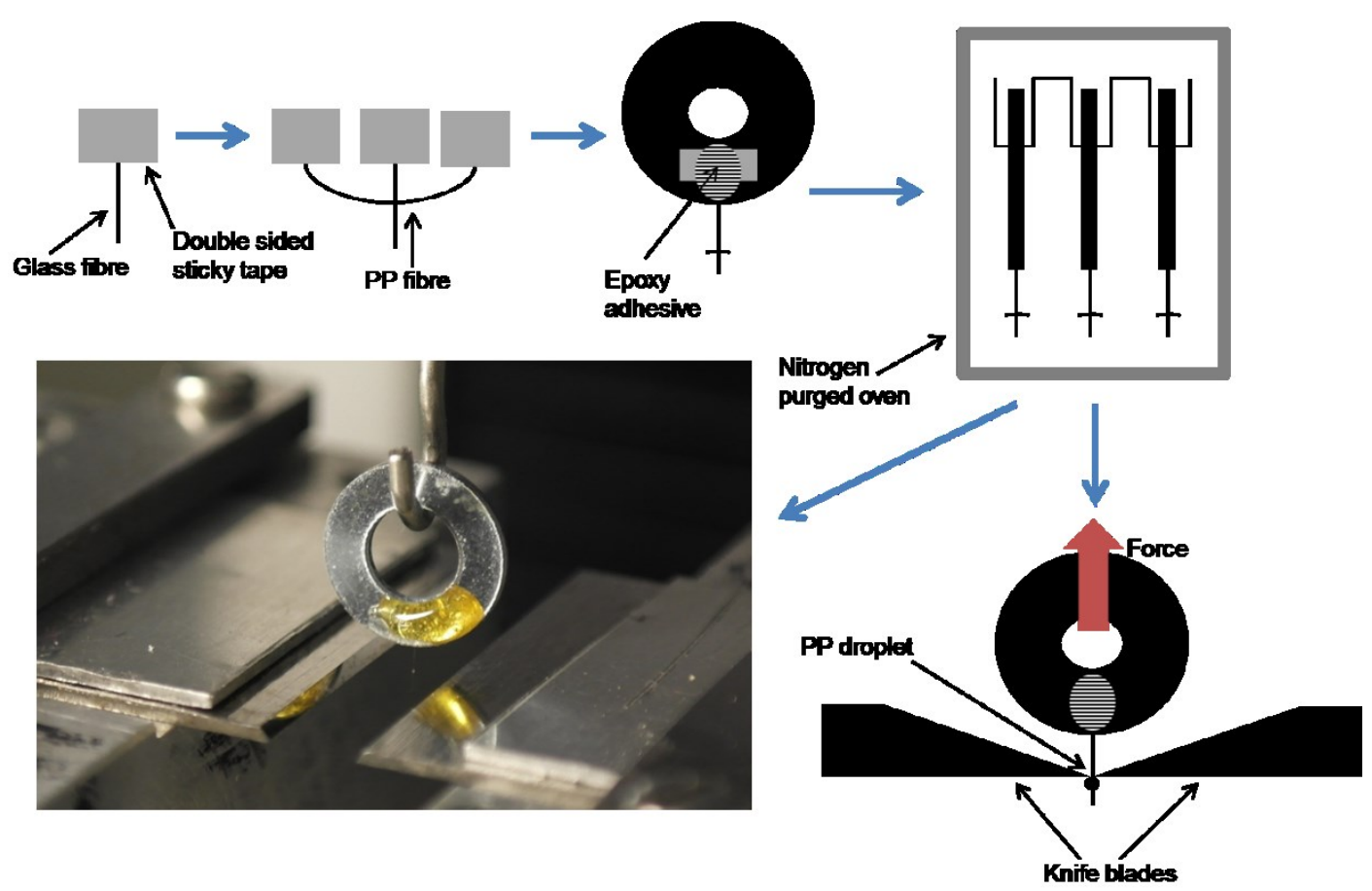

Figure 1. Microbond sample preparation

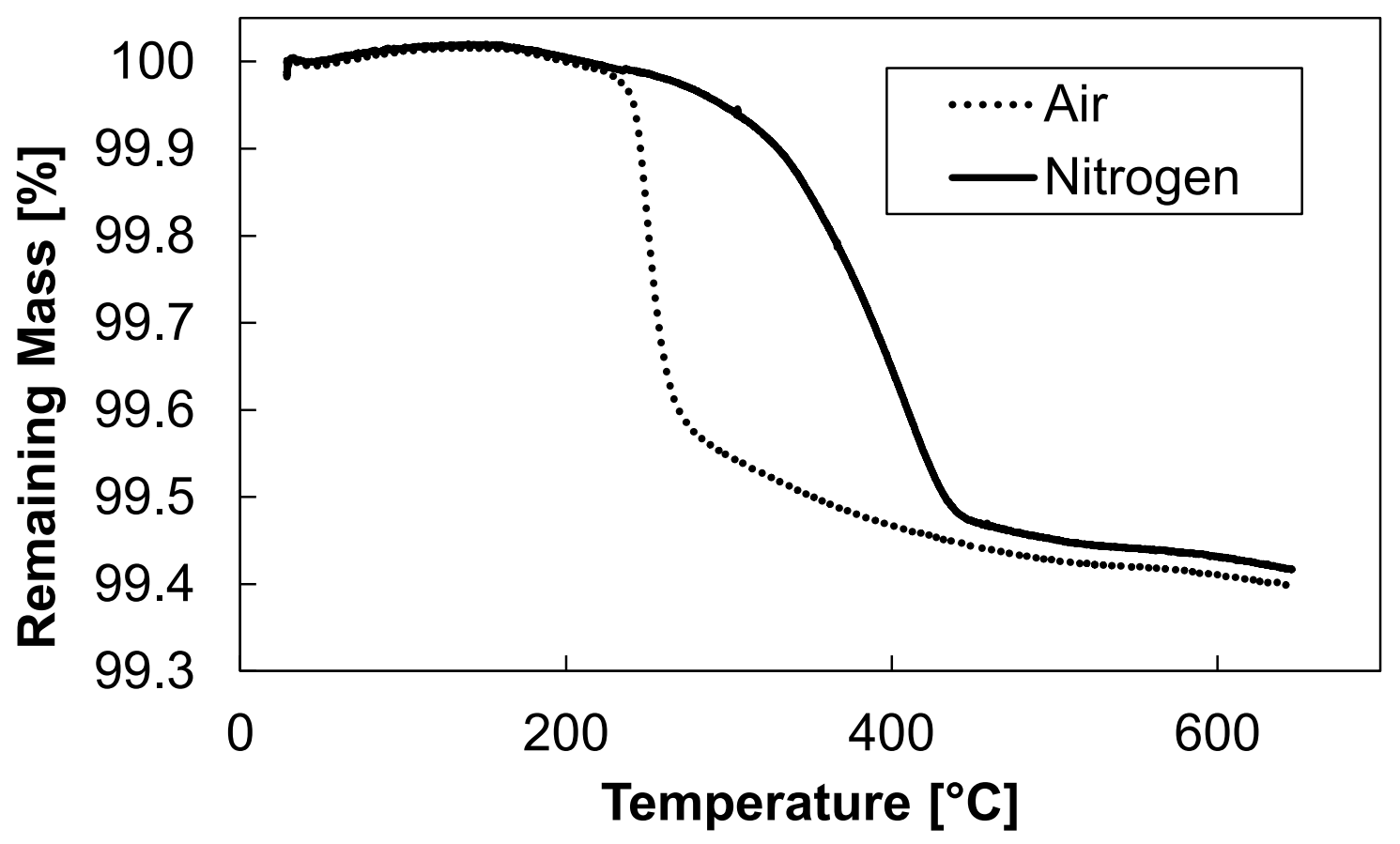

Figure 2. Thermal gravimetric analysis of chopped glass fibers with PP optimized sizing 


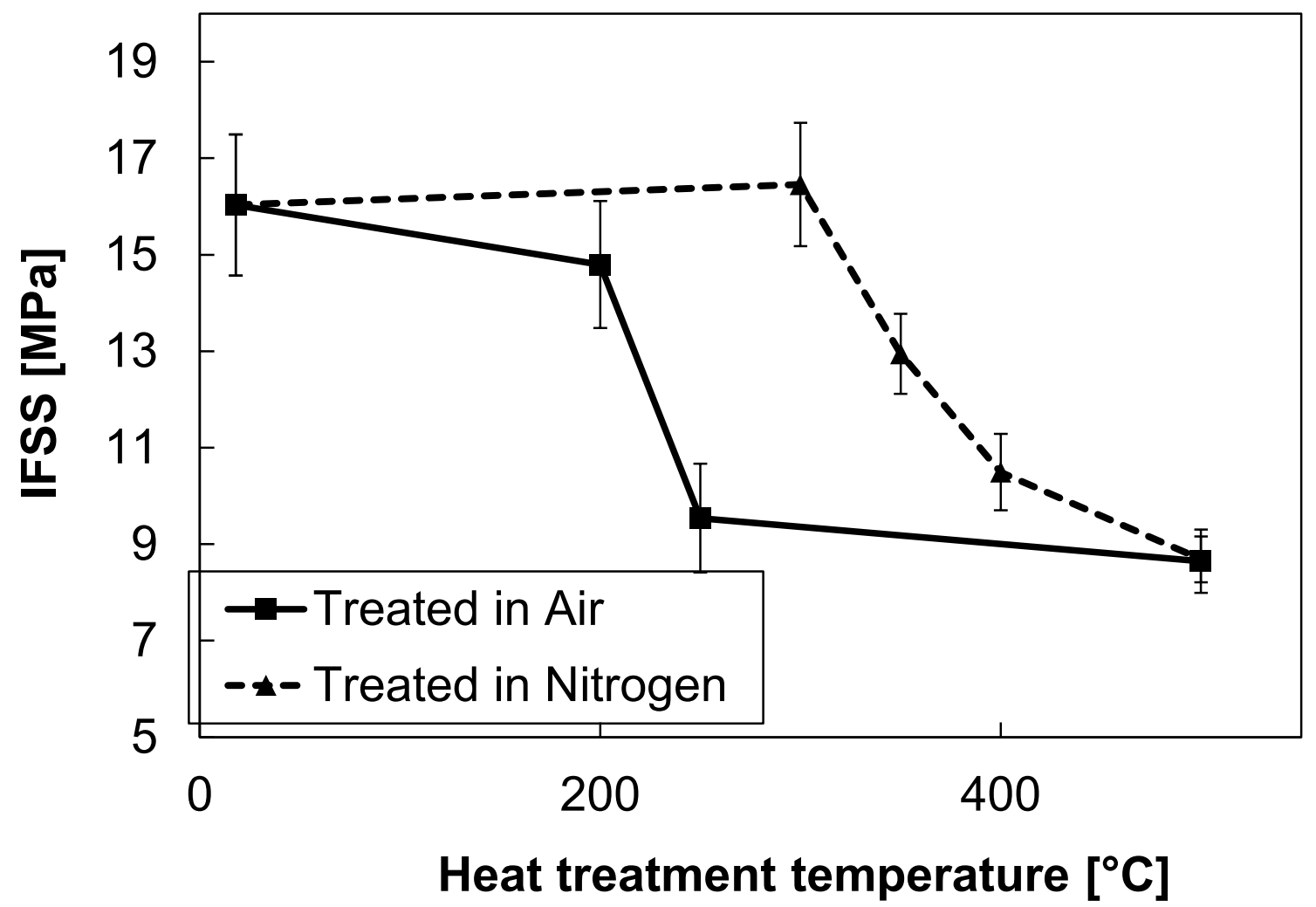

Figure 3. Effect preconditioning (temperature and atmosphere) on the apparent IFSS 


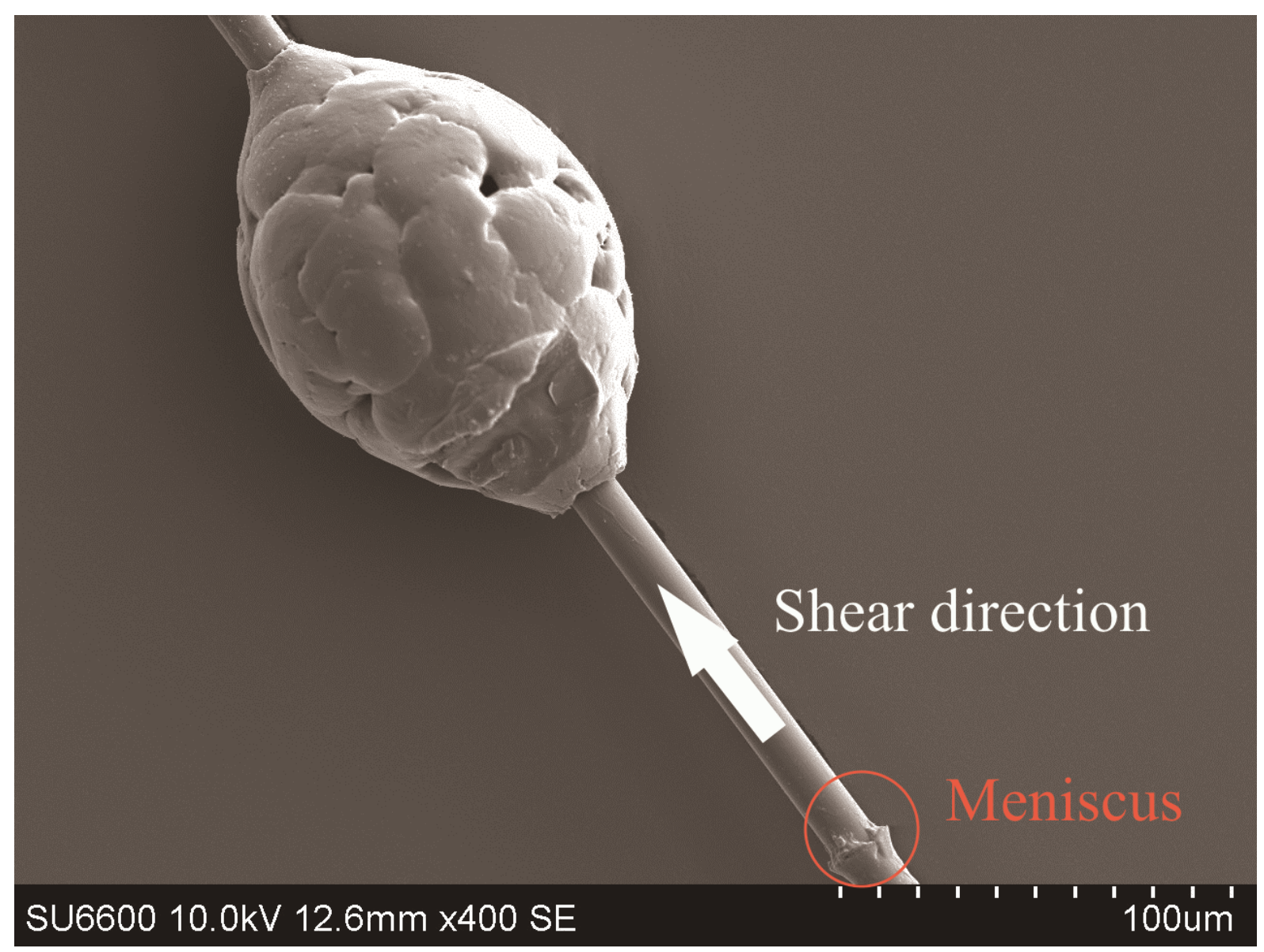

Figure 4. Debonded microbond sample (Fiber not thermally preconditioned) 


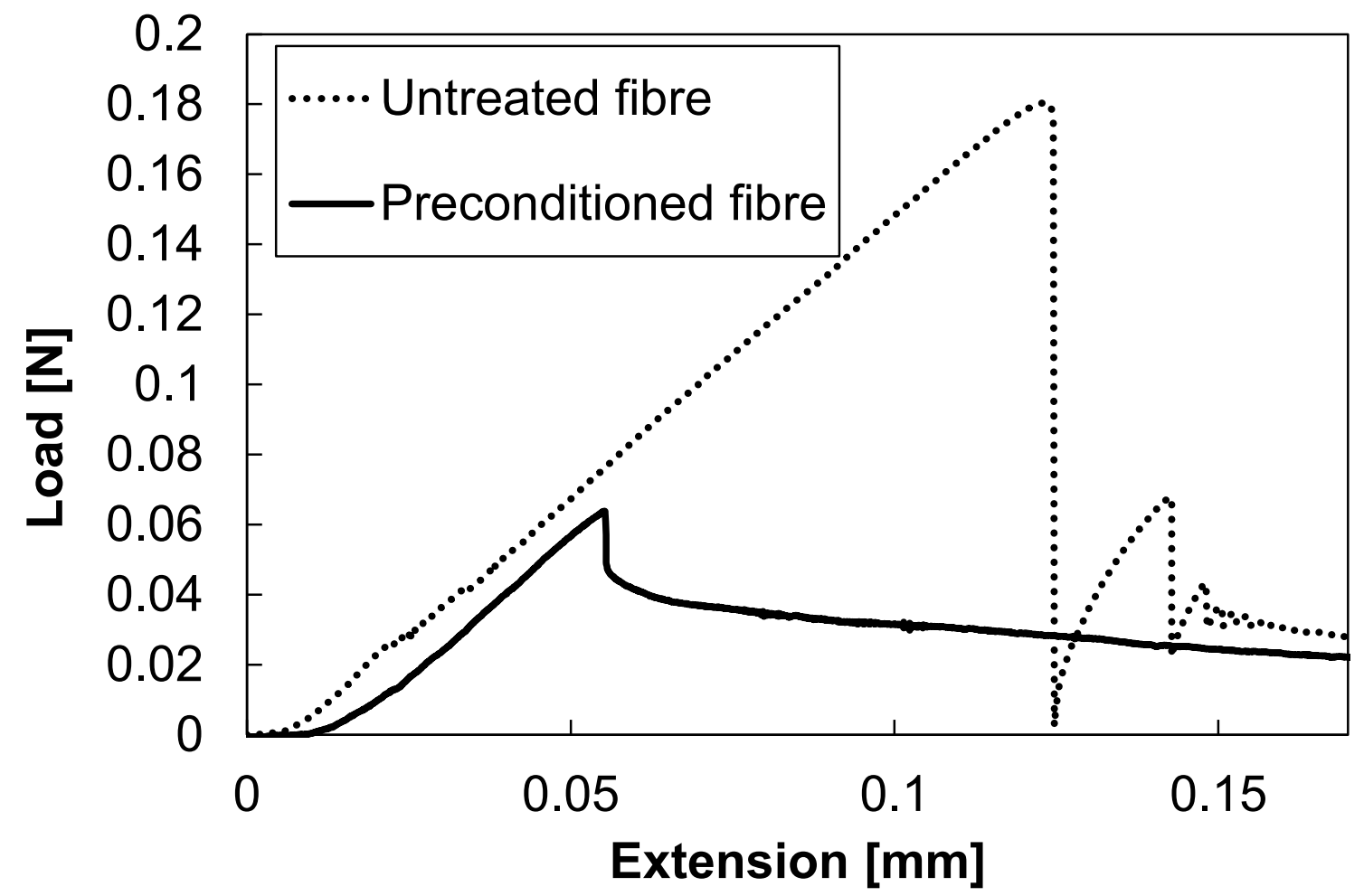

Figure 5. Load vs. extension of sample with "as received" fiber and thermally preconditioned fiber $\left(500^{\circ} \mathrm{C}, 25 \mathrm{~min}\right)$ 


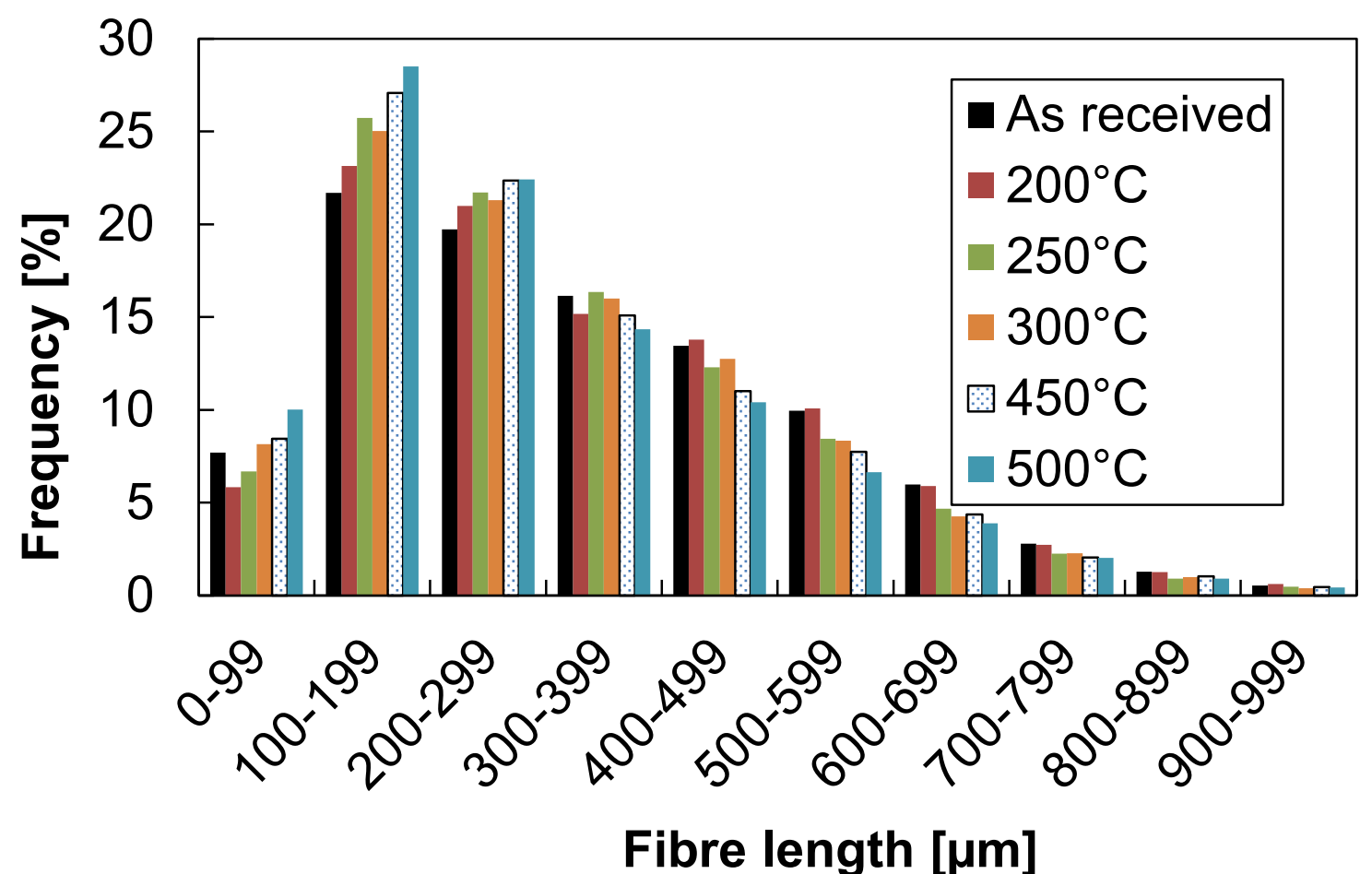

Figure 6. Length distributions of thermally preconditioned fibers in composites

Table 1. . Mean values and standard deviations of fiber length distributions

\begin{tabular}{cccc}
\hline $\begin{array}{c}\text { Fiber preconditioning } \\
\text { temperature }\end{array}$ & $\begin{array}{c}\text { Arithmetic mean of } \\
\text { length of distribution }\end{array}$ & $\begin{array}{c}\text { Standard deviation of } \\
\text { length distribution }\end{array}$ & $\begin{array}{c}\text { Standard deviation } \\
\text { between repeat } \\
\text { measurements }\end{array}$ \\
\hline As received & $343 \mu \mathrm{m}$ & $209 \mu \mathrm{m}$ & $2 \mu \mathrm{m}$ \\
$200^{\circ} \mathrm{C}$ & $342 \mu \mathrm{m}$ & $200 \mu \mathrm{m}$ & $3 \mu \mathrm{m}$ \\
$250^{\circ} \mathrm{C}$ & $321 \mu \mathrm{m}$ & $191 \mu \mathrm{m}$ & $7 \mu \mathrm{m}$ \\
$300^{\circ} \mathrm{C}$ & $318 \mu \mathrm{m}$ & $194 \mu \mathrm{m}$ & $5 \mu \mathrm{m}$ \\
$450^{\circ} \mathrm{C}$ & $308 \mu \mathrm{m}$ & $190 \mu \mathrm{m}$ & $11 \mu \mathrm{m}$ \\
$500^{\circ} \mathrm{C}$ & $296 \mu \mathrm{m}$ & $189 \mu \mathrm{m}$ & $3 \mu \mathrm{m}$ \\
\hline
\end{tabular}




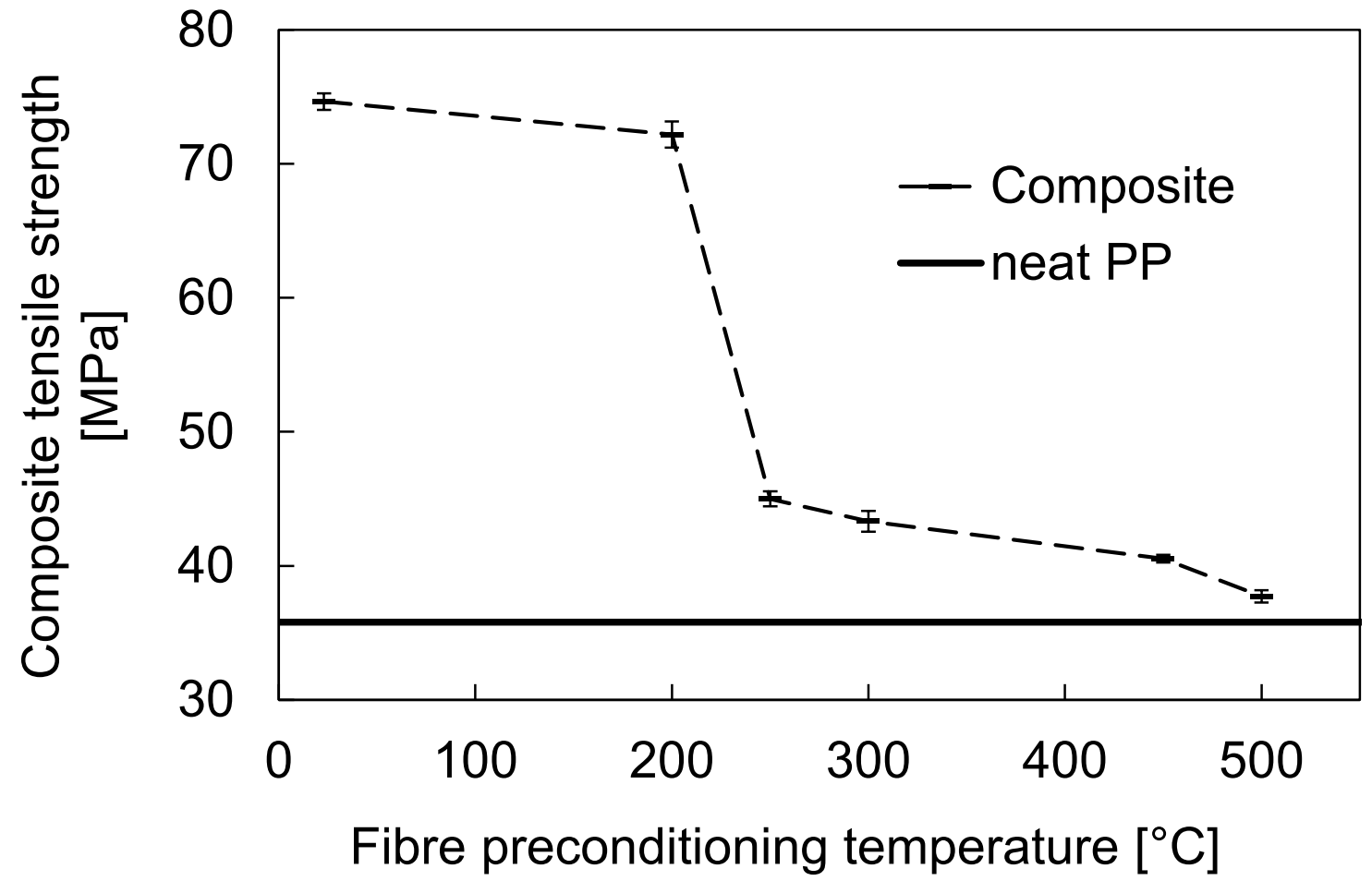

Figure 7. Maximum tensile stress versus fiber preconditioning temperature 


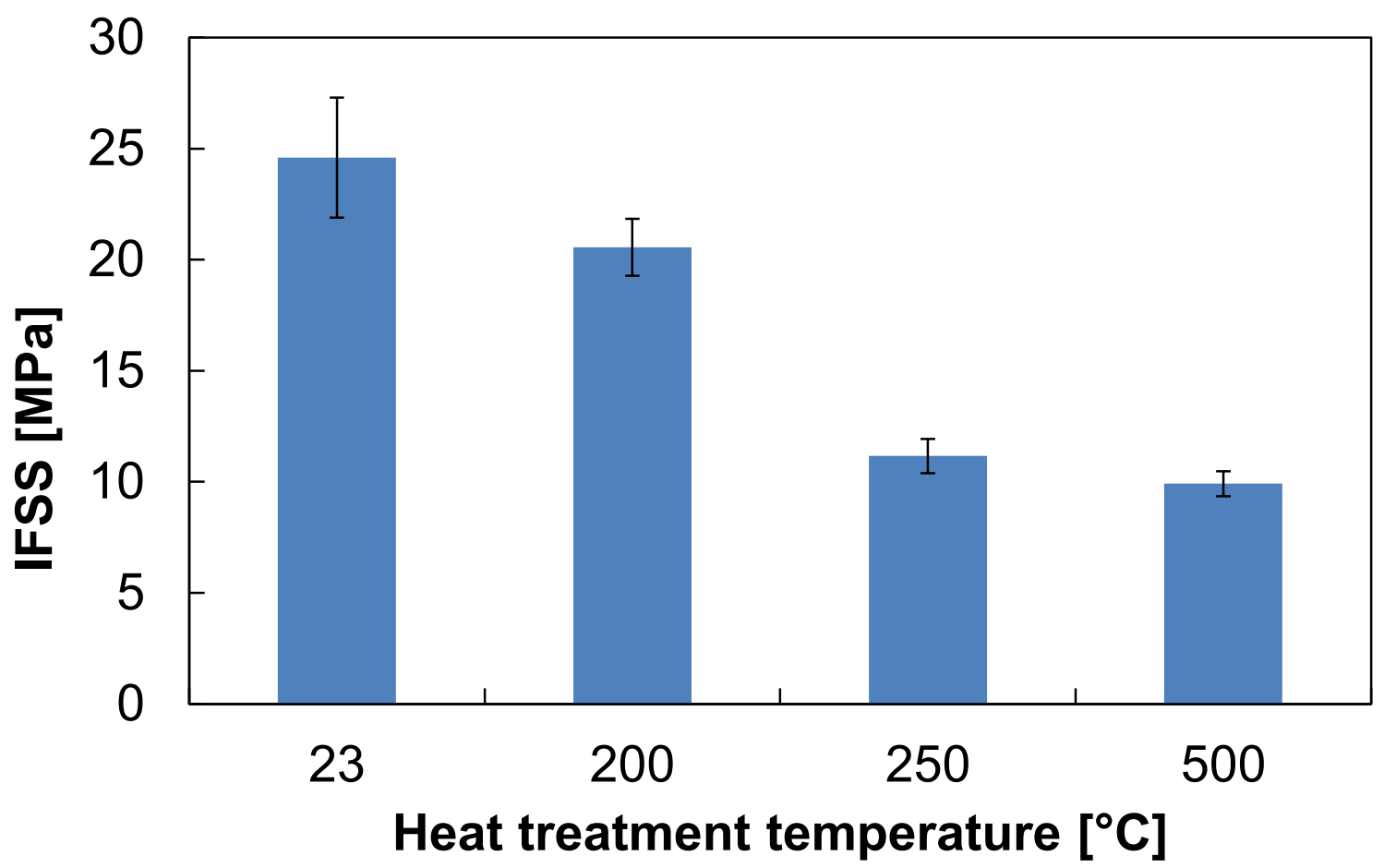

Figure 8. Apparent IFSS between thermally preconditioned fibers and PP with added MAPP 


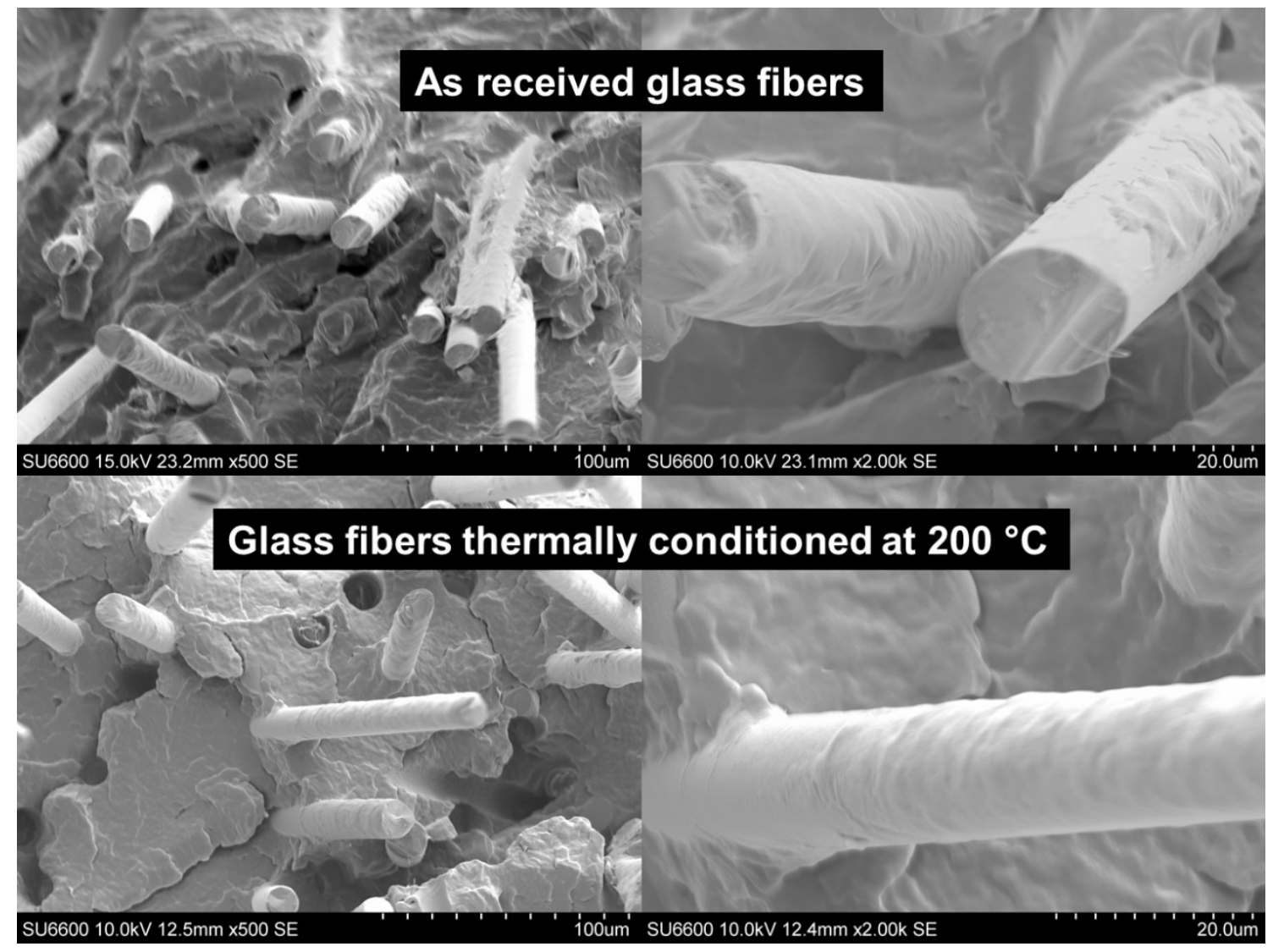

Figure 9. Fracture surface of a PP composites reinforced with as received fibers and thermally preconditioned fibers $\left(200^{\circ} \mathrm{C}\right)$ 


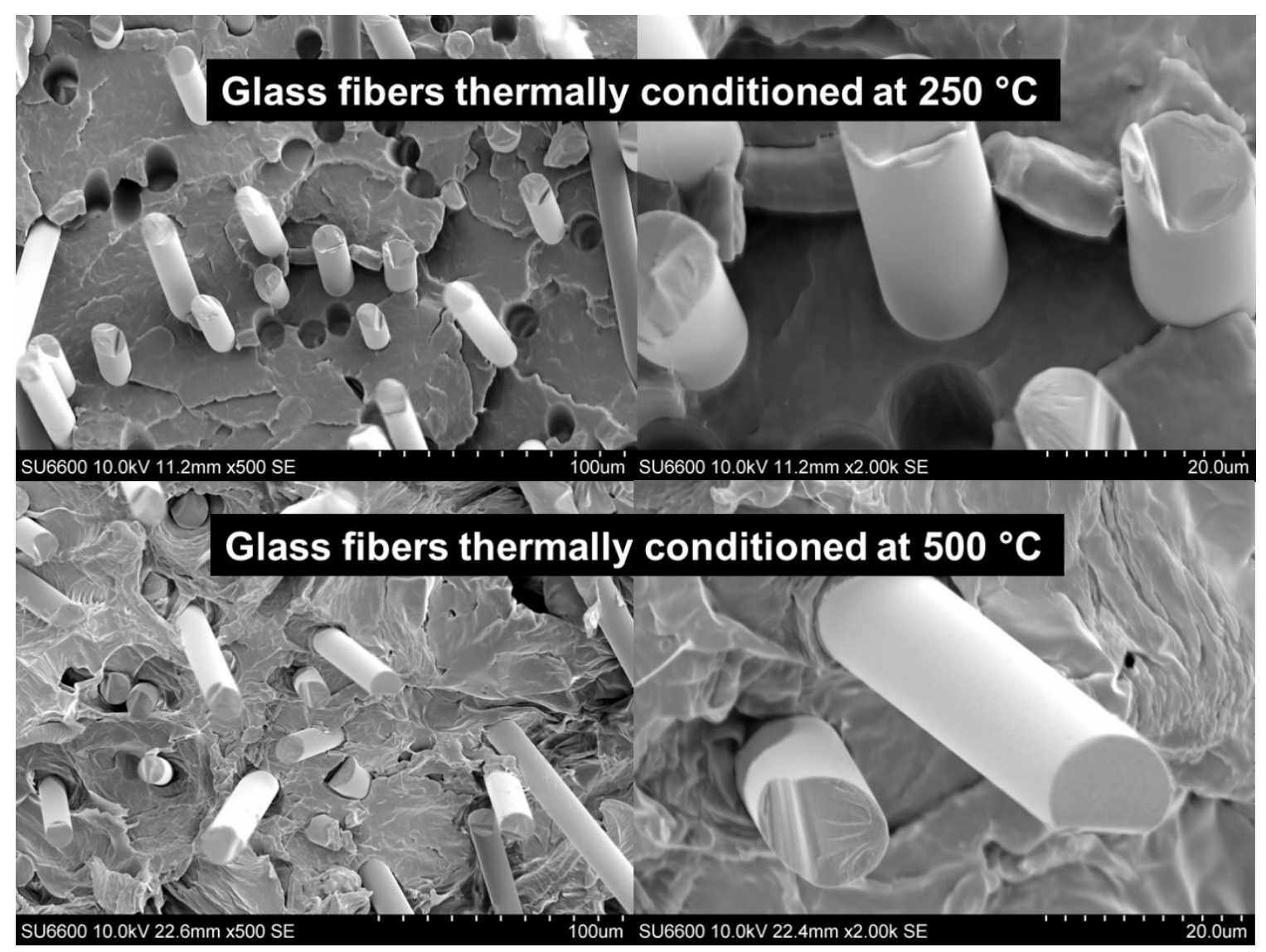

Figure 10. Fracture surface of PP composite reinforced with thermally preconditioned fibers $\left(250^{\circ} \mathrm{C}\right.$ and $\left.500{ }^{\circ} \mathrm{C}\right)$ 


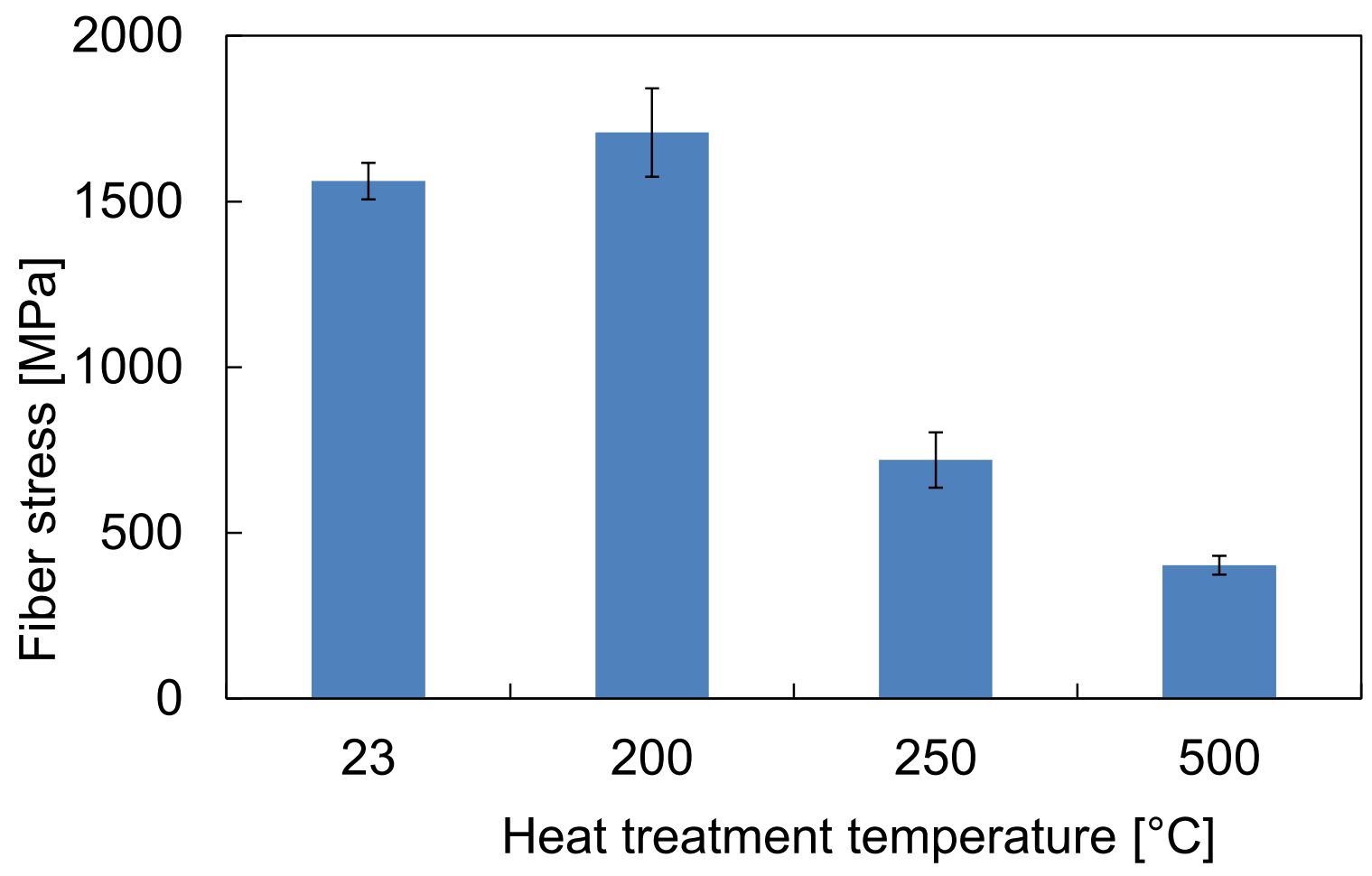

Figure 11. Calculated fiber stress at composite failure vs. fiber preconditioning temperature

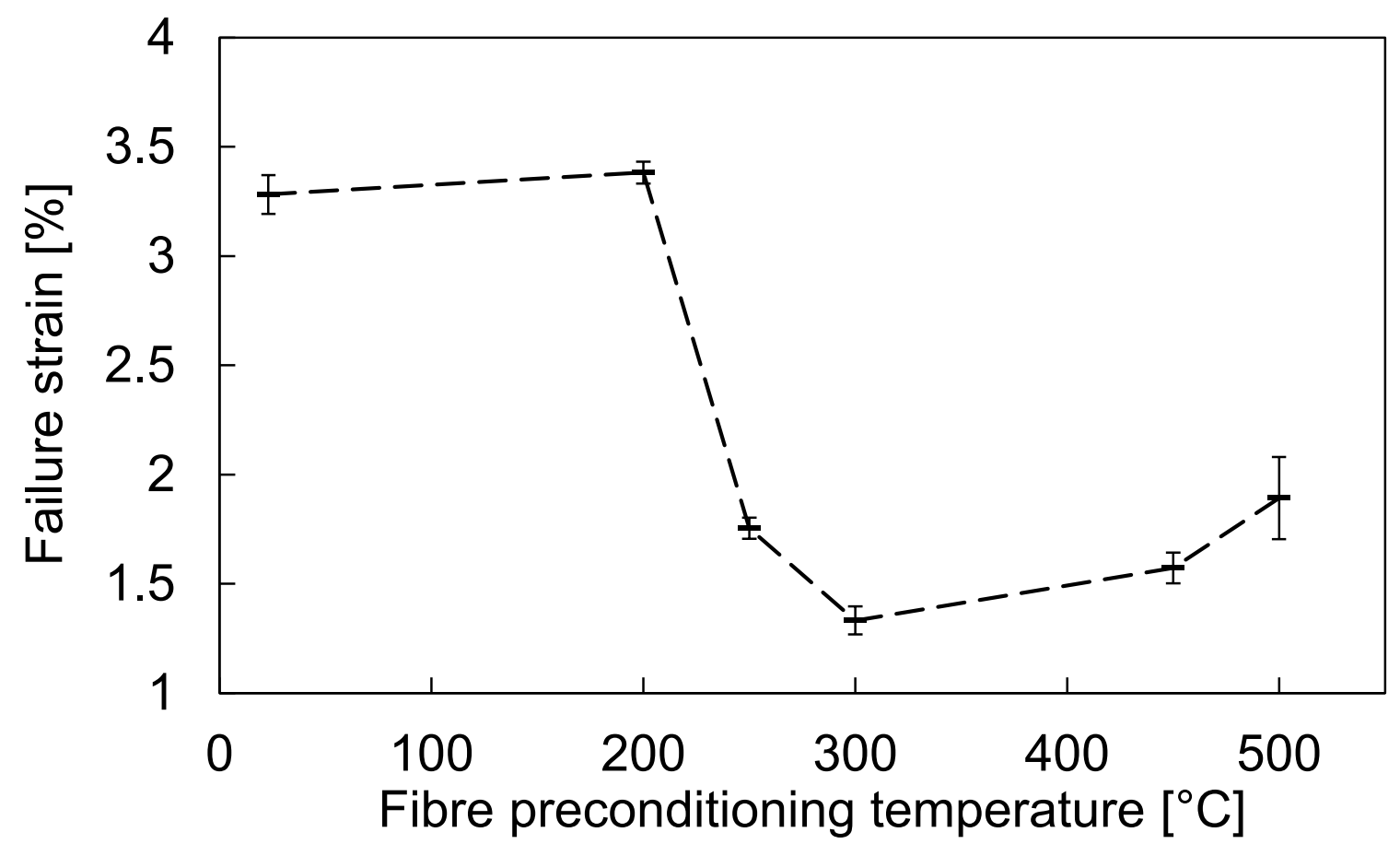

Figure 12. Composite failure strain versus fibre preconditioning temperature 


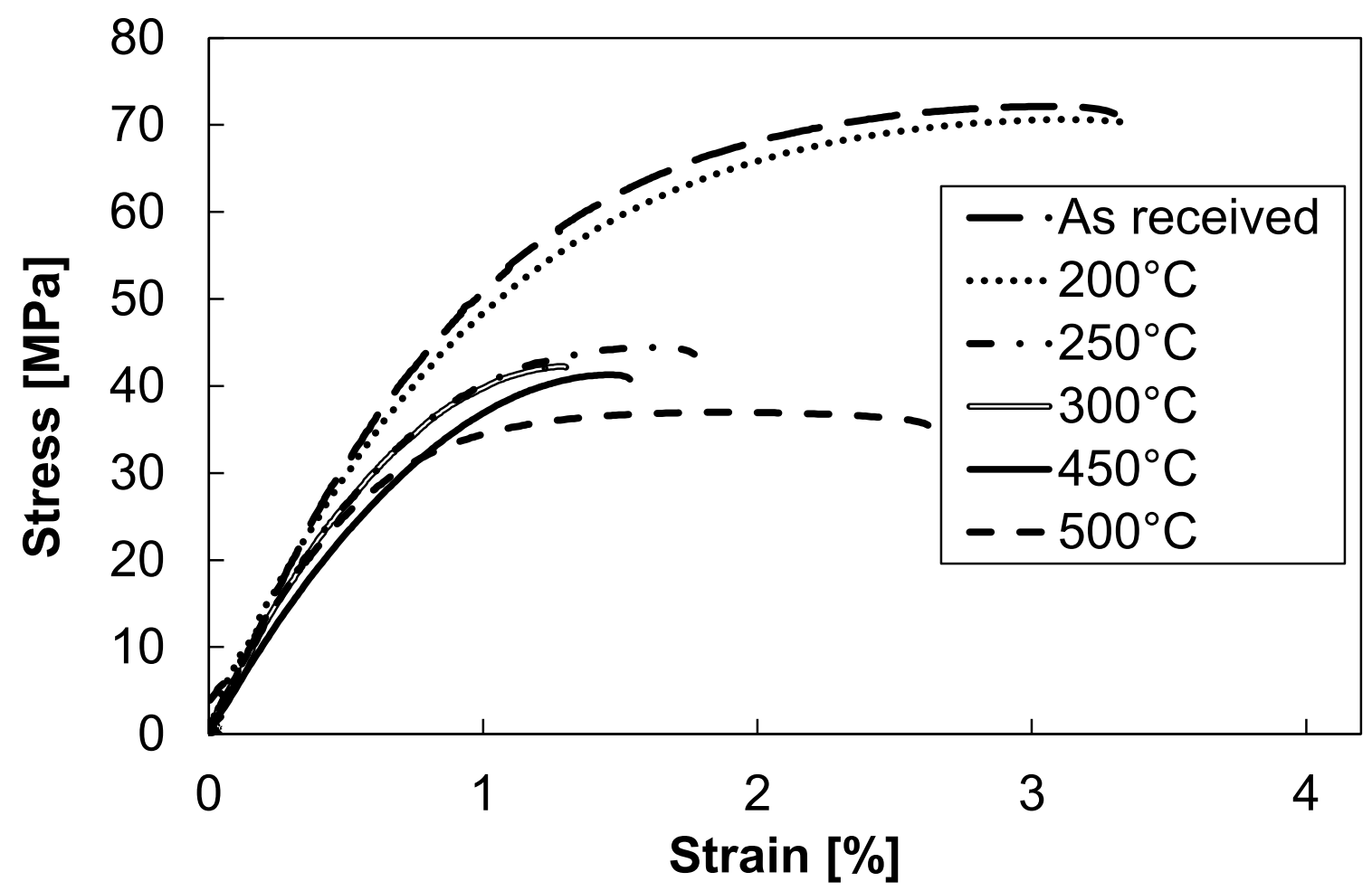

Figure 13. Stress-strain curves of composites based on thermally preconditioned glass fibers 